\author{
Michelle Pinto Lima \\ Instituto Federal de Educação, Ciência e Tecnologia do Piaú
}

\title{
As mulheres na Ciência da Computação
}

\begin{abstract}
Resumo: O objetivo deste trabalho é compreender a inserção de mulheres na Ciência da Computação. Buscou-se conhecer as percepções de professoras e professores a respeito da inserção das mulheres nessa área e as estratégias acionadas por elas para afirmarem-se nesse ambiente androcêntrico. Metodologicamente, realizou-se um estudo exploratório de natureza qualitativa com a utilização de entrevistas em profundidade com 12 docentes da área. Consideraram-se as percepções de ambos os sexos sobre o fenômeno, pois, como afirma Michelle Perrot, ${ }^{1}$ não se pode pensar na história das mulheres sem considerar os homens. Os resultados indicam que há formas sutis de discriminação e segregação das mulheres na área, exigindo delas esforço adicional para terem o mesmo reconhecimento que os homens.
\end{abstract}

Palavras-chave: mulheres; ciência; computação.

Copyright $\odot 2013$ by Revista Estudos Feministas.

${ }^{1}$ Michelle PERROT, 2005.

${ }^{2}$ Natália de Oliveira FONTOURA e Roberto GONZALEZ, 2009.

3 INSTITUTO BRASILEIRO DE GEOGRAFIA E ESTATÍSTICA, 2010.

\section{Introdução}

Ao longo dos últimos anos, foi constatado um aumento progressivo da participação das mulheres no mercado de trabalho. Segundo dados apontados por Fontoura e Gonzalez, ${ }^{2}$ a taxa de participação delas passou de 54,15\% em 2001 para $57,58 \%$ em 2008 . Ainda que isso represente um avanço importante na inserção delas no mundo do trabalho formal, é preciso considerar as dificuldades para entrar no mercado de trabalho e nele permanecer.

Ao considerar os índices educacionais, as mulheres apresentam níveis de escolaridade mais elevados do que os dos homens. Segundo os dados do IBGE, ${ }^{3}$ enquanto $61,2 \%$ das trabalhadoras tinham 11 anos ou mais de estudo, ou seja, pelo menos o ensino médio completo, o percentual de homens com esse mesmo nível de estudo era de apenas $53,2 \%$. Se considerarmos o percentual de mulheres ocupadas que possuem nível superior completo, elas somam $19,6 \%$, enquanto os homens representam apenas $14,2 \%$.

Ainda que esses dados sejam favoráveis à mulher, maior nível de escolaridade não garante a elas 
${ }^{4}$ INSTITUTO BRASILEIRO DE GEOGRAFIA E ESTATÍSTICA, 2010.

${ }^{5}$ Regina MADALOZZO, 2008.

${ }^{6}$ MADALOZZO, 2008

${ }^{7}$ INSTITUTO NACIONAL DE ESTUDOS E PESQUISAS EDUCACIONAIS, 2006.

${ }^{8}$ Fabrício MARQUES, 2007 9 Maria Eulina P. de CARVALHO, 2006 equiparação salarial com os homens. Informações da Síntese de Indicadores Sociais ${ }^{4}$ destacam que, mesmo sendo mais escolarizadas do que os homens, o rendimento médio delas continua sendo inferior ao deles. As mulheres ocupadas ganham em média $70,7 \%$ do que recebem os homens, diferença que fica mais acirrada quando ambos têm 12 anos ou mais de estudo (nesse caso, elas recebem $58 \%$ em comparação ao salário que eles recebem). Esses dados apontam que elas ainda sofrem processos de discriminação e desvalorização profissional.

Mas o maior nível de escolaridade tem possibilitado a ampliação da participação delas no campo da ciência, nas diversas áreas do ensino superior e em diferentes profissões que historicamente foram consideradas espaços masculinos, como aponta Madalozzo. ${ }^{5}$ Segundo essa autora, entre 1978 e 2007, o sexo feminino conquistou postos de trabalho em diversas profissões tradicionalmente masculinas. Em 1978, por exemplo, havia apenas 4,94\% de mulheres engenheiras. Em 2007, a participação feminina nesse setor passou para $10 \% .^{6}$ No entanto, esse avanço ainda está muito aquém para considerar que existem iguais oportunidades de trabalho para ambos os sexos em todas as profissões.

Ainda que haja maior participação feminina no universo da ciência e na produção do conhecimento, o Informativo do INEP' mostra a segregação de gênero em diversas áreas. Os cursos de graduação mais procurados pelos homens são relativos a áreas das exatas, tais como engenharia, tecnologia, indústria e computação. Nesta última, a concentração de homens chega a $79,9 \%$, ou seja, entre os que estão na Ciência da Computação, apenas $20,1 \%$ são mulheres.

Essa constatação foi feita também pela presidenta da Sociedade Brasileira da Computação e professora da Unicamp, Cláudia Bauzer Medeiros. Ela afirma que, além de ser reduzido, esse número de mulheres ainda tem diminuído desde meados dos anos 90 . Na graduação a quantidade de mulheres caiu de $30 \%$ para 5 ou $10 \%$. Em relação ao número de professoras, varia entre $25 \%$ a $30 \%$ do total. ${ }^{8}$

Estudos de Carvalho' indicam que, nos percentuais de matrícula e graduação por sexo na UFPB, as Ciências da Computação têm acumulado índices extremamente desiguais de participação entre os sexos. No ano de 2000 , $74,1 \%$ do corpo discente era formado por homens. No ano de 2005 , esse número foi ainda maior, saltando para $92,1 \%$. As mulheres, que em 2000 somavam $25,9 \%$ dos alunos, cinco anos depois eram apenas $7,9 \%$. 
10 Judith GLOVER, 2002.

${ }^{11}$ Margaret RAGO, 1998.
Esses números não refletem apenas a situação brasileira, pois internacionalmente Glover ${ }^{10}$ aponta que o nível de representação das mulheres nas ciências da computação varia entre 9 e $25 \%$. Em 1985, nos EUA e no Canadá, o número de mulheres na graduação em computação era de $37 \%$ e, em 2000 , esse número caiu para $28 \%$. Nas escolas superiores dos EUA, o número está abaixo de $20 \%$.

Em tempos em que as mulheres estão ocupando áreas tradicionalmente marcadas pela presença masculina e nelas avançando, como nas engenharias, como se explica o fato de, na Ciência da Computação, este número estar diminuindo? Com o objetivo de compreender as percepções de docentes a respeito da inserção dessas mulheres, consideradas minorias em uma área tradicionalmente marcada pela presença masculina, é que este trabalho foi motivado. Para tanto, buscou-se conhecer as percepções a respeito das relações entre professores e professoras dessa área e as possíveis estratégias acionadas por elas para afirmarem-se nesse ambiente androcêntrico.

Este trabalho está dividido em cinco partes além desta introdução. Na primeira, trataremos da ciência enquanto constituída historicamente de modo a adotar métodos e discursos que excluíssem as mulheres, garantindoIhe objetividade e neutralidade de uma ciência pura. Na segunda parte trataremos do tema Relações de Gênero e Computação, apresentando os estereótipos ligados à relação da mulher com a tecnologia e computação. Na terceira parte, a metodologia para a realização do estudo será apresentada, seguida dos resultados encontrados. Por último, seguem as conclusões obtidas com este trabalho.

\section{A ciência androcêntrica}

Na tentativa de compreender a relação entre ciência e mulheres, é impossível desconsiderar as relações sociais de gênero historicamente construídas. Apesar dos avanços das mulheres em diversas áreas e profissões, a ciência moderna ainda é caracterizada como masculina e exclui as mulheres de diversas formas, seja pela manutenção de redutos de homens, como acontece nas engenharias, na física, na matemática e na computação, seja pela invisibilidade de seus feitos.

Os principais pontos da crítica feminista à ciência, segundo Rago, ${ }^{11}$ incidem na denúncia de seu caráter particularista, ideológico, racista e sexista: a ciência universal é historicamente androcêntrica, branca, ocidental, heterossexual e localizada nas classes mais abastadas da sociedade, desconsiderando todos aqueles que escapam desse modelo de referência. 
${ }^{12}$ Sandra HARDING, 1996.

${ }^{13}$ Evelyn Fox KELLER, 1989.

${ }^{14}$ RAGO, 1998

${ }^{15}$ Londa SCHIEBINGER, 2001.
Para essa autora, os métodos e discursos na produção do conhecimento exigem racionalidade e objetividade para o alcance da verdade pura e universal. Tal neutralidade exigida na padronização da normatividade científica é impregnada por valores masculinos. Objetividade está associada ao masculino e subjetividade, ao feminino, sendo necessário, pois, excluir as mulheres dessa interferência na ciência. Portanto, os parâmetros legítimos da ciência são androcêntricos.

Para ser legitimado, o saber científico exigia que a/o cientista mantivesse distância do seu objeto de estudo, lançando um olhar neutro e objetivo sobre o fenômeno e alienando sua própria inserção sócio-histórica no mundo. Uma análise que envolve a atuação das mulheres nas diversas áreas da ciência passa por esse questionamento do seu caráter androcêntrico. Harding ${ }^{12}$ argumenta que 0 conhecimento científico legitimado é aquele que dá preferência ao modelo quantitativo e ao raciocínio linear, o que é associado ao homem.

Keller, ${ }^{13}$ numa tentativa de fazer uma ciência independente do gênero, procurou compreender a gênese da divisão sexual e emocional do trabalho, que rotulava mente, razão e objetividade como masculinas, e o coração (corpo), sentimento e subjetividade como femininos. Tal separação é utilizada somente para provocar a exclusão das mulheres do que é considerado científico. Na sua visão, uma ciência melhor era uma ciência mais abrangente e acessível às mulheres.

Para romper com essa hierarquia de funcionamento da ciência que cria dualidades entre objetivo e subjetivo, racional e emocional, mente e corpo, realidade e aparência, totalidade e parcialidade, cultura e natureza, sujeito e objeto, racional e emocional, ciências duras (hard sciences) e ciências moles (soft sciences), emerge uma nova relação entre teoria e prática, próximas uma da outra e que, segundo Rago, ${ }^{14}$ é capaz de construir novos significados na interpretação do mundo, os quais incorporam as dimensões anteriormente duais. Nessa nova relação entre teoria e prática, delineia-se um novo agente epistêmico, não isolado do mundo, isento e imparcial, mas subjetivo e particular.

Em seu livro "O feminismo mudou a ciência?", Schiebinger ${ }^{15}$ focaliza a inter-relação entre questões de gênero e os modos de fazer ciência. A oposição entre o feminismo liberal, que vê as mulheres como iguais aos homens, e o feminismo da diferença, construída pela cultura e não pela natureza, orientam a discussão sobre a inserção da mulher na ciência. $O$ feminismo da diferença considerava necessária uma reavaliação de qualidades desvalorizadas pela sociedade e que seriam tradicionalmente femininas, 
16 SCHIEBINGER, 2001, p. 24.

${ }^{17}$ SCHIEBINGER, 2001.

${ }^{18}$ Jane Soares de ALMEIDA, 1998

${ }^{19}$ ALMEIDA, 1998, p. 32. tais como subjetividade, cooperação, sentimento e empatia. Para a corrente do feminismo liberal, as mulheres poderiam se tornar iguais nas ciências se houvessem mudanças nos currículos, laboratórios, teorias, prioridades e programas de pesquisa. ${ }^{16}$

Essa autora apresenta pontos positivos e entraves para a análise da inserção das mulheres nas ciências em cada uma dessas correntes. O feminismo da diferença refutava a ideia de considerar que a ciência fosse de gênero neutro, uma vez que os valores atribuídos às mulheres foram excluídos e serviram para construir a desigualdade na estrutura do conhecimento. No entanto, a ideia dessa corrente era prejudicial para as mulheres e a ciência porque considerava a universalização da mulher, como se entre elas não houvesse diferenças de classe, raças, orientações sexuais, diferentes histórias, necessidades e expectativas. Além disso, ressaltar qualidades consideradas intrinsecamente femininas para fazer ciência só serve para reafirmar velhos estereótipos que por muito tempo justificaram a exclusão da mulher na construção do saber científico.

A autora afirma que nenhum desses modelos, feminista ou liberal, é suficiente para resolver o problema de centenas de anos de exclusão das mulheres. Seriam necessárias profundas mudanças estruturais na cultura, métodos e conteúdo da ciência. ${ }^{17}$ As relações de poder estabelecidas entre os sexos também passam pela questão do saber, pois conhecimento e poder estão necessariamente interligados, como argumenta Almeida. ${ }^{18} \mathrm{O}$ desejo de manter o dominado (mulher) longe do saber foi e continua sendo uma estratégia eficiente no controle e na manutenção de mecanismos de dominação.

A educação e profissionalização das mulheres, colocadas em segundo plano, geraram ambiguidades quanto à posição feminina, representada pelo equilíbrio entre a condição desejável e a possível de se obter. ${ }^{19}$ Para alcançar esse equilíbrio, o magistério tornou-se a saída, pois era aceitável que as mulheres desempenhassem um trabalho, desde que significasse cuidar de alguém, uma vez que essa é a uma qualidade inerente à mulher. As atribuições femininas jamais poderiam prever a concorrência com os homens em termos profissionais e intelectuais, pois isso significaria ameaçar o rompimento da ordem social estabelecida.

A sociedade ocidental, organizada em um sistema de patriarcado, excludente dos direitos e anseios das mulheres, admite que o lugar social da mulher no âmbito público e profissional é na docência. Como possibilidade de efetiva inserção nesse meio, muitas mulheres se sentiram atraídas 
${ }^{20}$ Maria Christina S. de S. CAMPOS e Vera L. G. da SILVA, 2002.

${ }^{21}$ Guacira LOURO, 1997.
22 BRASIL, 2010.

${ }^{23}$ COORDENAÇÃO DE APERFEIÇOAMENTO DE PESSOAL DE NÍVEL SUPERIOR, 2007. pela profissão, provocando uma entrada maciça delas na metade do século XX, gerando um fenômeno conhecido como feminização do magistério. ${ }^{20} \mathrm{~A}$ docência era vista como uma forma de ampliação da função feminina fundamental que é a maternidade, com um desdobramento do que ela já faz em casa com seus filhos. Segundo Guacira Louro, ${ }^{21}$ cada aluno é considerado um filho ou filha espiritual, fazendo do exercício do magistério uma extensão do próprio lar.

No Brasil, a situação que se configura em benefício dos homens indica que as mulheres estão em diversas áreas da ciência, mas sua representatividade em todas as áreas e em diferentes níveis ainda fica a desejar para que se tenha uma paridade entre os sexos. Dados estatísticos do Diretório dos Grupos de Pesquisa do Conselho Nacional de Desenvolvimento Científico e Tecnológico (CNPq), do Ministério da Ciência e Tecnologia, referentes ao censo de 2010 , indicam que elas eram $45,08 \%$ das pesquisadoras, enquanto eles eram $54,87 \%$ entre os que ocupavam posição de liderança. ${ }^{22}$ Em números absolutos, 16.802 eram mulheres e 20.452 , homens. Já entre os não líderes, a proporção de homens e mulheres é equilibrada, com uma pequena maioria de mulheres, que soma $51,46 \%$, e $48,30 \%$ homens.

Segundo dados do mesmo censo, as mulheres estão sempre em minoria entre os pesquisadores líderes. A análise da faixa etária que vai dos 24 anos até 65 ou mais mostra que, no começo da carreira, elas somam apenas $25 \%$ do total desse grupo de pesquisadores, aumentando gradativamente sua inserção em outras faixas etárias, alcançando até $48,04 \%$ entre os líderes, quando a faixa etária em que se encontram é entre 50 a 54 anos. Isso mostra que o tempo levado para se firmar como líder é bastante demorado, o que não acontece com os homens. A análise da liderança entre os/as pesquisadores/as permite constatar que, independentemente da faixa etária, os homens sempre estão em maioria em relação às mulheres.

A participação das mulheres na docência também aumentou, mesmo que de forma tímida. Em 2010, elas representavam $44,3 \%$ do total de docentes no país, o que significa um aumento de $3,5 \%$, se comparado a $2005 .{ }^{23}$ As áreas em que elas são mais numerosas são Ciências Humanas, Saúde e Ciências Sociais Aplicadas, mantendo a tradição que o patriarcado deixou como legado.

Para se pensar a mulher docente é necessário levar em consideração sua identidade social e culturalmente construída no jogo dessas relações sociais e sexuais, pelas práticas disciplinadoras e pelos discursos/saberes instituintes. No imaginário social, tudo o que constitui sua identidade como mulher precisa ser considerado para que este sujeito, 
${ }^{24}$ BEAUVIOR, 1975.

${ }^{25}$ Helena HIRATA e Danièle KERGOAT, 2007.

${ }^{26}$ Heleieth SAFFIOTI, 1992.

${ }^{27}$ Silvia C. YANNOULAS, 2007.

${ }^{28}$ Margaret ROSSITER, 1980 citado por SCHIENBINGER, 2001. antes definido como o segundo sexo ${ }^{24}$ ou sexo frágil, possa gozar de sua emancipação.

\section{Relações de gênero e Computação}

A maior presença das mulheres no ensino superior e na pós-graduação não modificou significativamente suas escolhas disciplinares. Isso demonstra que, embora compartilhando de uma universidade que recruta indiscriminadamente homens e mulheres, as trajetórias discentes e, consequentemente, docentes, são diferenciadas. Isso evidencia que as relações de gênero instituídas na sociedade influenciam a formação do vínculo com o conhecimento, criando a divisão sexual do trabalho também no campo da ciência.

Para Hirata e Kergoat, ${ }^{25}$ essa divisão das relações sociais entre os sexos são moduladas histórica e socialmente. Enquanto homens são destinados à esfera produtiva, sendo a isso adicionado valor social, às mulheres cabe a esfera reprodutiva e, em decorrência disso, um trabalho de homem vale mais do que um trabalho de mulher. Mas antes mesmo da separação hierárquica, que determina quem deve ser o dominador e quem é o dominado, está o princípio de separação dos sexos em relação ao trabalho para determinar trabalhos de homens e trabalhos de mulheres. A legitimidade de tais princípios estão presentes em todos os tipos de sociedade, legitimados por uma ideologia naturalista que relaciona gênero ao sexo biológico, reduzindo as práticas sociais a papéis sociais sexuados.

A conexão entre gênero e sexo é apresentada por Heleieth Saffioti. ${ }^{26}$ Para ela, a trajetória para a construção das relações de gênero é percorrida a partir do social em direção ao biológico, e não do biológico para o social. Com isso, tudo o que se constrói a respeito dos sexos são oriundos do que socialmente se construiu a respeito deles. Silvia C. Yannoulas ${ }^{27}$ ressalta que não se pode ficar alheio às questões que envolvem as relações de gênero, uma vez que educação é uma prática social. Como tal, os estereótipos sexuais socialmente atribuídos a mulheres e homens, a feminização de determinadas carreiras, as formas de discriminação explícitas ou sutis, a autodiscriminação no acesso, o androcentrismo no conhecimento científico, os códigos e lógicas das esferas pública, privada e social são alguns dos fatores que precisam ser levados em consideração. O universo dos computadores não se configura como uma exceção da esfera social.

No início da década de 1980, Margaret Rossiter ${ }^{28}$ propôs dois conceitos para compreender as estatísticas sobre mulheres na ciência e as desvantagens que continuavam a sofrer: segregação hierárquica e segregação 
${ }^{29}$ SCHEINBINGER, 2001, p. 166.

${ }^{30}$ INSTITUTO NACIONAL DE ESTUDOS E PESQUISAS EDUCACIONAIS, 2010

${ }^{31}$ Betina Lankard BROWN, 2001.

${ }^{32}$ WILSON, 2003. territorial. No primeiro, quanto maior é a escalada do poder e prestígio, menor é o número de mulheres. Na "segregação territorial", os campos de atuação de homens e mulheres são demarcados. Elas se agrupam em disciplinas, tendendo a ensinar e pesquisar mais em humanidades e ciências sociais do que em ciências naturais, exatas e engenharias. A maior concentração de mulheres é nas chamadas ciências soft: as ciências da vida e do comportamento e as ciências sociais. Poucas mulheres são encontradas nas ciências hard. Quanto mais soft a ciência, maior a taxa de participação feminina. Nas áreas da ciência e tecnologia, território mapeado pelos homens, as mulheres, já desconsideradas nas áreas científicas, são também assim tratadas na área tecnológica.

Como tecnologia é considerada coisa de homem, as mulheres que exercem a docência têm outro desafio, relacionado aos estudantes. Comportamentos tradicionalmente femininos entram em conflito com as expectativas dos estudantes em relação à postura professoral: eles tendem a avaliar as mulheres estereotipicamente femininas como menos competentes que mulheres que se apresentam de uma maneira mais profissional. ${ }^{29}$ Scheinbinger cita, por exemplo, que os estudantes podem fazer questionamentos para as professoras que não fariam para professores, por achar difícil e inaceitável a autoridade de uma mulher em áreas dominadas pelos homens ou até mesmo para testar seus conhecimentos.

Na perspectiva da segregação territorial, as mulheres continuam sendo minorias e sub-representadas, especialmente quando se trata das carreiras relacionadas à tecnologia, como no caso da Computação e da Informática. Esse registro não acontece apenas no Brasil, onde o percentual de homens no curso é de $79,9 \%,{ }^{30}$ mas também em outras regiões do mundo. Brown ${ }^{31}$ cita que, segundo a Associação Americana de Mulheres Universitárias, o número de licenciadas em Ciências da Computação e Tecnologia da Informação está diminuindo, apesar da necessidade crescente de trabalhadores nessas áreas.

Apesar do aumento no número de cursos de computação nas universidades e dos altos salários pagos para profissionais da computação, o número de mulheres presentes nessa área está em queda. Segundo Wilson, ${ }^{32}$ estatísticas produzidas pela Higher Education Statistical Agency mostram que mulheres representavam apenas $19 \%$ dos estudantes na Ciência da Computação no ano 2000.

Em tempos em que as mulheres estão ocupando maior espaço no mercado de trabalho, incluindo os diversos campos da ciência, e estão em maior número no ensino superior, qual a explicação para a diminuição delas nessa 
${ }^{33}$ WILSON, 2003.

${ }^{34}$ WILSON, 2003.

${ }^{35}$ SCHEINBINGER, 2001.

${ }^{36}$ Clevi Elena RAPKIEWICZ, 1998 área da ciência? Wilson ${ }^{33}$ argumenta que existe uma associação entre homem e tecnologia. Tecnologia é associada com algo potente, incompreensível, desumano, científico e, sobretudo, masculino.

Mas a autora ressalta que a suposta alienação das mulheres à tecnologia é um produto da construção histórica e cultural da tecnologia como masculina. A masculinidade é parcialmente construída através de noções de competência técnica. A dominação masculina permanece principalmente pela duradoura associação simbólica entre masculinidade e tecnologia, imagens culturais e representações de tecnologia, que convergem com a imagem de masculinidade e poder.

Para ela, os estereótipos sexuais são produzidos e reproduzidos. A computação geralmente é associada à ambição, tenacidade, obstinação, exibindo perfeita combinação com as características androcêntricas da ciência: objetividade, racionalidade, distância emocional (neutralidade) do objeto. As mulheres e sua subjetividade possuem um estilo considerado diferente pela ciência, separando-se dos homens pela sua forma de pensar e trabalhar. Essa diferenciação, na opinião de Wilson, ${ }^{34}$ gera dois efeitos.

O primeiro é que o maior interesse da mulher em tecnologia ameaça a imagem de si mesma, como feminina. Para Scheinbinger ${ }^{35}$ isso ocorre porque a identidade de gênero denota como um homem ou uma mulher se apropriam individualmente de aspectos da ideologia de gênero como parte de seu senso do eu. Essas identidades podem até variar contextualmente, conforme o homem ou a mulher percebam o comportamento como mais ou menos adequado ao contexto social. No entanto, é essa expressão do eu que irá nortear a atribuição de gênero pelos outros. Os corpos constantemente operados em mulheres pelos discursos do que deve ser e como deve agir a mulher entram em constante disputa com os valores e práticas projetadas pela cultura da ciência.

Em segundo lugar, as mulheres são marcadas por serem "inferiores", possuindo habilidades de valor inferior. É conhecido que as mulheres na profissão da informática não podem ser tecnicamente competentes, mesmo quando qualificadas, sendo dados para elas postos de trabalho mais servis ou que são supervisionados mais de perto. Constatação disso no Brasil encontra-se nos estudos de Rapkiewicz, ${ }^{36}$ cujos resultados denotam que há maior participação feminina como mão de obra nas funções que exigem menor qualificação, como na função "operador". A autora ressalta que só há maior feminilização aí devido à grande quantidade de desligamentos dos homens na área, 
${ }^{37}$ Betina Stefanello LIMA, 2008.

${ }^{38}$ Fiona WILSON, 2003.
${ }^{39}$ Flis HENWOOD, 2000

${ }^{40}$ WILSON, 2003. talvez porque os salários sejam mais baixos e eles prefiram as ocupações de analistas e programadores, cuja hierarquia é mais alta na área e os salários são melhores.

Num habitat natural dos homens que conjuga características do público e da ciência, pessoas fora do lugar são levadas a provar sua capacidade de sobrevivência. Daí a busca da perfeição e do fazer mais como tentativa de provar suas habilidades. Lima $^{37}$ fala de uma posição híbrida no sistema de relações, ou seja, para serem minimamente aceitas, as mulheres são testadas, colocadas à prova pelos homens e valores por eles construídos.

Para Wilson ${ }^{38}$ não é que falte às mulheres competências para o exercício da profissão. Na escola, elas até mostram superioridade em relação aos meninos em várias áreas de programação, mas falta-lhes incentivo. Além disso, os meninos passam por um processo de socialização com a tecnologia antes de ingressarem na universidade, o que lhes proporciona um conhecimento prévio de informática e torna os processos posteriores de aprendizagem muito mais tranquilos e agradáveis do que para as meninas. As mulheres também tendem a subestimar sua competência nas habilidades técnicas associadas com a computação e continuam a equiparar competência e habilidade técnica com masculinidade. ${ }^{39}$

Os estudos de Wilson ${ }^{40}$ apontam que as características estereotipadas do cientista da computação também podem contribuir para um menor interesse das mulheres na área: sexo masculino, antissocial, obsessivo e passa o dia e a noite sentado na frente do computador, fascinado com a máquina. Os resultados de sua pesquisa apontam que garotas de $15 \mathrm{e}$ 16 anos se desligam da carreira que envolve computadores porque acham os jogos violentos e imaturos. Quando elas escolhem jogos e softwares, preferem os altamente qualificados em vez dos que "matam muito". É como se os softwares fossem criados por homens e para eles, provenientes da área e de quem, supostamente, se interessa por ela.

Na área da Informática e Computação, os registros históricos que apagam a participação das mulheres não foi diferente do que ocorreu em outras áreas da ciência, que privilegiam no espaço púbico as realizações dos homens. Como ressalta Rapkiewicz, ${ }^{41}$ em meados do século $\mathrm{XIX}$, Ada Byron se tornou a primeira mulher a construir algoritmos que permitiam que máquinas pudessem computar valores de funções matemáticas. Somente no século seguinte, mais precisamente em 1980, na Inglaterra, é que as anotações e os experimentos de Ada foram oficialmente considerados como o primeiro esboço de um software na história; ou seja, a primeira pessoa a desenvolver um programa de computador foi uma mulher. 
Outros nomes importantes do cenário feminino na área são Grace Murray Hooper, inventora da linguagem de programa COBOL, e hoje Marissa Ann Mayer, vice-presidente do departamento do Google para produtos de pesquisa e experiência do usuário. As contribuições dadas pelas mulheres na área de Informática foram principalmente na evolução do software, trabalho que o/a cientista desenvolve sozinho/a ou em equipe, mas não atende ao público, como aponta a autora. Permanecendo no espaço privado, essas mulheres ficavam distantes dos olhares do público. Diante da invisibilidade delas, a história da Informática é contada com base na evolução do hardware e suas diferentes gerações, publicando apenas feitos dos homens.

Programas que incentivam o interesse feminino pelas carreiras na área da computação têm se difundido. O Grace Hopper Celebration of Women in Computing (GHC), o Congresso Latino-americano de mulheres em Informática (LAWCC), o IT Girls (programa feito pela Comissão Europeia para implementar boas práticas para mulheres no setor da Inovação, Ciência e Tecnologia) são alguns dos incentivos atualmente promovidos para a estimular a entrada de mulheres nessa área da ciência, como aponta Marques. ${ }^{42}$ Justin Rattne, diretor de tecnologia da Intel, afirma: "as companhias dependem do talento e da experiência das mulheres para competir globalmente". Além disso, as mulheres são consideradas um fator-chave para ampliar o interesse das novas gerações pela computação, como afirma a professora da Unicamp e ex-presidente da Sociedade Brasileira de Computação Cláudia Bauzer: "se os jovens se desinteressam, os países perdem espaço na economia global. A atração das mulheres significa, no longo prazo, que filhos e familiares também se envolvam nesse tipo de carreira."

Mas por que a participação feminina na ciência e tecnologia é importante? Esse movimento para maior entrada de mulheres na área não se relaciona apenas à questão da diversidade, da quebra de mitos construídos sobre a mulher na área de tecnologia. Vai além disso quando a sua inserção na área se relaciona com o poder de influência que a mulher exerce sobre outras gerações, já que a ela é delegada a tarefa de ensinar os filhos, típico de uma sociedade patriarcal. A mulher, professora, que educa.

As discriminações contra a mulher ainda são muitas e precisam ser conhecidas como forma de quebrarmos barreiras naturalizadas pela herança patriarcal, as quais dificultam ou mesmo impedem a concretização dos seus direitos. No exercício da docência, as relações de gênero permeiam as relações entre homens e mulheres que trabalham em uma mesma instituição, em um mesmo departamento. Mesmo em número reduzido, e em declínio, a entrada de mulheres na 
${ }^{43}$ Joan SCOTT, 1995.

${ }^{44}$ PERROT, 2005.
45 INSTITUTO BRASILEIRO DE GEOGRAFIA E ESTATÍSTICA, 2009. 46 INSTITUTO BRASILEIRO DE GEOGRAFIA E ESTATÍSTICA, 2010.

47 BRASIL, 2007

${ }^{48}$ BRASIL, 2006

49 BRASIL, 2009.

${ }^{50}$ Maria C. S. MINAYO, 2007. computação provocou modificações nas relações sociais dentro das instituições. Como pertencente a uma categoria de análise histórica com aspecto relacional, qualquer estudo que envolve gênero não pode ser conduzido separadamente, pois designa relações sociais entre sexos, estando aí inclusos construções culturais, aspectos estruturais e ideológicos em torno de tais relações. ${ }^{43}$

É com esse interesse em compreender as relações entre os sexos em uma determinada área da ciência, predominantemente marcada pela presença de homens, que surgiu a curiosidade de trabalhar com essa temática. Para tanto, não se pode partir apenas do ponto de vista das mulheres, pois, como afirma Michelle Perrot, ${ }^{44}$ não se pode pensar na história das mulheres sem considerar os homens, uma vez que elas interagem com eles continuamente, na função de maridos, pais, irmãos, filhos e, mais especificamente neste estudo, como colegas de trabalho.

\section{$4 \mathrm{Em}$ busca de respostas}

Em uma fase exploratória, buscou-se identificar, a partir da literatura disponível e de conversas informais com professores e professoras de Computação e Informática, as percepções a respeito da inserção das mulheres nessa área da docência, um campo demarcado pelo grande número de homens. Para identificar a distribuição deles e delas nas áreas da Computação e da Informática, foram utilizados dados secundários divulgados pelo IBGE (2009 e 2010) ${ }^{45,46 .}$ pela CAPES (2007) ${ }^{47}$ e pelo INEP (2006 e 2009). ${ }^{48,49}$

A opção pela pesquisa qualitativa visou buscar uma aproximação da referência subjetiva subjacente às manifestações da realidade. ${ }^{50}$ Foi utilizada a entrevista individual em profundidade, tendo em vista a necessidade deste estudo de explorar o assunto a partir da busca de informações, percepções e experiências do conjunto dos entrevistados.

O período dessa coleta de dados deu-se de novembro a dezembro do ano de 2010 e os/as entrevistados/ as não tiveram seus nomes identificados, com a finalidade de garantir o anonimato. Participaram deste estudo seis professores e seis professoras da área de Computação e Informática. Tais docentes estão vinculados/as a instituições públicas e privadas do país que oferecem cursos de nível superior na referida área. A finalidade de envolver neste estudo docentes que trabalham em Estados diferentes foi para captar diferentes percepções de indivíduos inseridos em diferentes contextos sociais e profissionais.

O critério de escolha ou seleção dessas pessoas foi a disponibilidade apresentada por elas para participar da 
${ }^{51}$ Chris MANN e Fiona STEWART, 2004 pesquisa. Páginas eletrônicas de instituições de ensino superior foram visitadas de modo a conferir a listagem de professores e professoras da área para a obtenção dos seus endereços eletrônicos para envio do convite de participação na pesquisa, no qual foram explicitados os objetivos da pesquisa e esclarecida a necessidade da entrevista e a forma de sua realização. Após o retorno obtido, procedeu-se às entrevistas, que foram realizadas obedecendo a disponibilidade de horário de cada um, previamente agendado. Essa etapa foi conduzida utilizando comunicação eletrônica síncrona, via MSN, e, por essa razão, foi possível realizar entrevistas com professores e professoras pertencentes a instituições localizadas nos estados de Minas Gerais, Rio de Janeiro, São Paulo e Piauí.

Mann e Stewart ${ }^{51}$ listam algumas vantagens das entrevistas on-line: ampliação do acesso a participantes; economia de custo e tempo; eliminação do viés em que se incorre nas transcrições. Ao final, tem-se o arquivo com a interação original, o que é prejudicado na transcrição de entrevistas face a face, devido à existência de muita linguagem não verbal. O manuseio dos dados torna-se mais fácil. Além disso, os autores ressaltam que a Internet é vista como um ambiente seguro, evitando o embaraço típico de interações pessoais.

Um roteiro da entrevista funcionou como um guia geral e focalizou algumas questões referentes a: (a) percepção quanto à diminuição do número de mulheres na computação e causa para essa possível ocorrência; implicações enfrentadas no exercício da profissão por ser mulher; (b) possível diferenciação no tratamento dispensado ao professor e à professora por parte do alunado; (c) percepção quanto ao relacionamento entre professores e professoras da área; adaptação feminina ao meio de maioria masculina; e (d) maneira de promover a atração de mulheres para a computação. Foi utilizado o mesmo roteiro nas entrevistas com algumas adaptações nas perguntas como forma de se ajustarem ao sexo da pessoa entrevistada.

No presente estudo, as questões foram submetidas a um pré-teste e os entrevistados julgaram adequadas e necessárias as perguntas para responder ao que foi proposto pelo objetivo da pesquisa. Como se trata de um estudo qualitativo, não se pretende estabelecer conclusões precisas e definitivas a respeito das informações obtidas, apenas identificá-las e integrá-las de modo que seja possível sintetizar as descobertas. 
52 SCHEINBINGER, 2008.

${ }^{53}$ Maria Eulina. P. de. CARVALHO, 2006.

${ }^{54}$ SAFFIOTI, 1992

\section{Percepções acerca da inserção da mulher na Ciência da Computação e Informática}

A divisão sexual do trabalho no campo da ciência marcada pela existência de áreas com grande concentração de mulheres, como as ciências sociais, e áreas com grande concentração de homens, como é o caso da computação e informática, não ocorre apenas pela demarcação de territórios para um e outro sexo, mas também no espaço de convivência entre eles no cotidiano do trabalho.

Nas entrevistas realizadas, todos os professores e professoras confirmaram que o número de estudantes do sexo feminino na computação tem diminuído, constando de duas ou três mulheres, no máximo, de um total de 40 alunos por turma. Essa baixa presença feminina na área é algo que tem se mantido constante e não é diferente da época em que os/ as entrevistados/as cursavam a graduação na área. Além disso, o número de mulheres que ingressam no curso não é igual ao número de alunas que o concluem, pois há bastante evasão delas durante o curso, como afirma o professor 4: "No começo do curso ainda é possível encontrar umas 6 mulheres, mas depois elas desistem e acabam ficando só umas 2".

Esse campo de atuação com territórios demarcados, denominado por Scheinbinger ${ }^{52}$ de Segregação Territorial, denota que a área da Computação ainda é pouco atrativa para as mulheres, confirmado pelo baixo número delas entre os que ingressam no curso. O progressivo aumento da inserção delas em carreiras em que a disputa por vaga é bastante acirrada, como na Medicina e no Direito, ${ }^{53}$ mostra que, mesmo que não haja barreiras formais ao seu acesso a quaisquer cursos superiores, a escolha do curso é decorrente do que socialmente se constrói a respeito dos sexos, como coloca Saffioti. ${ }^{54}$

$\mathrm{Na}$ reprodução cultural de qualidades inerentes à produção de ciência, estereótipos perduram e contribuem para criar uma identidade de gênero também na ciência, delimitando os campos de atuação de um e outro sexo. Isso promove a autodiscriminação de mulheres, que não fazem a opção pelo curso considerado como um reduto masculino. O que lhes é ensinado durante o processo de socialização é que "tecnologia é coisa de homem".

Além disso, a escolha de um curso não acontece de forma isolada. Essa decisão recebe a influência do meio social, depende de uma representação de si mesma, o que está fortemente relacionado com os papéis culturalmente atribuídos aos sexos, reflexos de uma identidade de gênero, 
${ }^{55}$ YANNOULAS, 2007

${ }^{56}$ SCHEINBINGER, 2001.

${ }^{57}$ Evelyn Fox KELLER, 1991.

${ }^{58}$ Guacira Lopes LOURO, 2003.

${ }^{59}$ WILSON, 2003. moldada pelos mitos, crenças e valores provenientes de sua cultura e dos quais a mulher dificilmente conseguirá se desvencilhar.

Como os valores atribuídos à verdade científica pura e válida universalmente são coincidentes com as características dos homens, as barreiras à entrada de mulheres na área das ciências exatas ficam mais fortes. No caso da computação e informática, não é apenas a entrada delas na universidade, mas o percurso e a sua permanência nessas áreas "masculinizadas" estão associados com os padrões culturais vigentes nas relações entre os sexos, como apontam Yannoulas ${ }^{55}$ e Scheinbinger. ${ }^{56}$

Os corpos operados em mulheres são permanentemente influenciados pelos discursos do que devem ser e de como devem agir. Em meio a uma maioria quase absoluta de homens, isso entra em constante disputa com os valores e práticas projetadas pela cultura nesse campo da ciência, que rotula mente, razão e objetividade como características puramente masculinas, como evidencia Keller. ${ }^{57}$

Os estereótipos sexuais atribuídos a homens e mulheres são revelados em discursos dos professores, que atribuem à cultura o fato de as mulheres não se interessarem por cursos das áreas das exatas. Eles reconhecem que é algo construído pela própria educação recebida dos pais, pelo modo de criar as meninas, que acabam por consolidar a cultura que é repassada. Conforme dito por um dos professores, "Apesar de não concordar, o machismo existe e nós tendemos a repetir comportamentos sem questionálos" (professor 2).

O trecho do discurso acima reflete como a diferença sexual é trazida para dentro do espaço escolar e é determinante desse processo histórico relacionado à exclusão das mulheres. Para Louro, ${ }^{58}$ a escola é um espaço social generificado, atravessado pelas representações de gênero. As normas e valores socioculturais internalizados pelas pessoas determinam os papéis e as atribuições de cada sexo no espaço social. Os papéis de gênero predominantes em cada grupo social afetam as trajetórias, escolhas e interesses que irão guiar a vida do indivíduo.

Um dos motivos que contribuem para a decisão de alunas em deixar o curso é, segundo professores, a discriminação sofrida pelo sexo oposto. Os alunos julgam que as habilidades delas são inferiores às deles, exatamente como aponta Wilson. ${ }^{59}$

Penso que além das dificuldades da graduação, comum a ambos os sexos, vai enfrentar o machismo e cultura desfavorável à escolha que teve. Os próprios colegas alunos menosprezando através de bullying, 
${ }^{60}$ Maria Celeste Reis Fernandes de SOUZA e Maria da Conceição Ferreira FONSECA, 2009.

${ }^{61}$ Lea VELHO, Elena LEÓN, 1998. algo como ela não sabe nada ou não se esforça (professor 5).

As alunas teriam muitas dificuldades com as disciplinas de lógica e de cálculo, segundo os respondentes. Como elas acontecem logo no início do curso, isso é um obstáculo difícil de transpor para muitas delas, o que provoca a desistência no curso.

Mais uma vez percebe-se a influência dos processos de socialização diferenciados para homens e mulheres na carreira científica. Como indicam Souza e Fonseca, ${ }^{60} \mathrm{O}$ caminho no qual se apoia a ideia de que "homem é melhor em matemática do que mulher" decorre da homogeneização de um certo modo de raciocinar, baseado na racionalidade cartesiana, produtora de um tipo de masculinidade na qual o valor do homem racional é permanentemente reafirmado. Sensibilidade, emotividade e afetividade são características que se distanciam dos caminhos da razão. Como tais características são associadas às mulheres, elas não são detentoras dessa racionalidade e, portanto, incapazes de fazer matemática.

Para Velho e León, ${ }^{61}$ o baixo interesse das mulheres nas ciências duras se dá de forma inconsciente. Em torno da sétima série, as meninas passam a manifestar menor habilidade para a matemática do que os meninos. Segundo as autoras, isto tem a ver com as expectativas e atitudes de pais e professores, que encorajam e motivam os meninos, mas não as meninas, para a Matemática. A partir de então, ela passa a ser "coisa de meninos", o que entra em conflito com a identidade sexual das meninas.

Os professores ressaltaram que, em sala de aula, quando há meninas, eles sempre procuram apoiá-las e ajudá-las, para que elas se sintam melhor durante o curso. Como nunca presenciaram as alunas sendo discriminadas, seus relatos derivam de comentários e de histórias contadas pelos alunos. Outros professores afirmaram que percebem que, para as alunas, a aprendizagem em certas disciplinas é mais demorada que para os homens, exigindo maior auxílio deles.

Mais uma vez o androcentrismo na ciência é evidenciado, colocando em um polo privilegiado as habilidades "naturais" do homem. Isso contraria a declaração de muitos professores (1, 2, 4 e 5), para os quais "homens e mulheres têm a mesma capacidade". Como ninguém pode falar explicitamente sobre a crença de que as mulheres são intelectualmente inferiores aos homens, mecanismos mais sutis para manter a homogeneidade masculina são utilizados.

Contrariamente a essa crença de igualdade de capacidades entre os sexos, as respondentes assinalaram que a distribuição de disciplinas durante o curso ocorre de 
62 ROSSITER, 1982 citado por SCHEINBINGER, 2001.

${ }^{63}$ HIRATA e KERGOAT, 2007.

${ }^{64}$ CAMPOS E SILVA, 2002 forma que as mais "complexas" ficam com os homens. Para elas, restam as outras disciplinas, mais fáceis. Na percepção dos professores, tradicionalmente as mulheres "não gostam" de algumas disciplinas, tidas como mais complexas. Por isso, geralmente essas disciplinas acabam sendo lecionadas por eles. Essa situação se configura como uma forma de discriminação territorial, termo cunhado por Margaret Rossiter. ${ }^{62}$ Nesse tipo de discriminação, as mulheres lecionam disciplinas específicas, para as quais são atribuídos menor valor.

Ainda que não haja diferenciação quanto à remuneração, pois todos ocupam o mesmo cargo, o conhecimento do homem é sobrevalorizado em detrimento do da mulher. O nível de complexidade do conteúdo a ser trabalhado na disciplina é um dos pontos de segregação das muIheres. Quanto maior o nível de complexidade, maior a racionalidade, objetividade e conhecimento exigidos. Segundo os parâmetros estabelecidos pelas ciências exatas, o homem reúne os requisitos necessários para lecionar tais conteúdos complexos. Tem-se aí mais um reforço para que permaneça a crença de que o trabalho de homem vale mais que o trabalho de uma mulher, como já colocava Hirata e Kergoat. ${ }^{63}$

Quando indagados/as sobre alguma diferenciação no tratamento dos/as alunos/as em relação ao docente em função do seu sexo, as professoras afirmaram que percebem maior aproximação do corpo discente com elas. Os/as alunos/ as sentem-se mais à vontade para fazer perguntas, pedir ajuda, não só em relação à disciplina lecionada pela professora, mas também naquelas trabalhadas pelos professores. Conforme dito por uma das professoras: "Os alunos têm mais liberdade pra falar e pedir ajuda pra gente, até de outras disciplinas, do que com professores" (professora 1). Os professores alegaram que não recebem feedback quanto a isso, porque nunca tiveram a oportunidade de observar a relação entre a professora e seus discentes para identificar diferenciação.

Os estereótipos relacionados aos papéis sexuais são reafirmados tanto por parte dos/as discentes quanto pelas professoras. Qualidades relacionadas à natureza feminina, como cooperação, empatia, passividade, emotividade, ternura e acolhimento, moldam as relações sociais entre elas e o alunado. As professoras, mulheres, e em razão disso consideradas mais dóceis e carinhosas que os homens, ${ }^{64}$ assumem sua identidade de gênero e, como um prolongamento das funções maternas na tarefa de instruir e educar, estão predispostas a ajudar o alunado em suas dificuldades.

Quanto ao reconhecimento de seu trabalho por parte dos alunos e alunas, as professoras afirmaram que precisam 
demonstrar que têm a mesma competência que os professores para serem tratadas sem discriminação. Segundo uma delas: "tem que se garantir" (professora 5). Essa percepção indica que a mulher precisa de um esforço adicional para provar que tem a mesma competência que os seus pares masculinos, algo que não é igualmente cobrado dos homens. Quando elas ocupam um lugar que não é propriamente aquele que a ciência escolheu para ela, a busca da perfeição, do fazer sempre mais, do ir além daquilo que seria natural caso fosse um homem, é uma tentativa das mulheres para sobreviverem nesse lugar e não serem consideradas inferiores em relação ao sexo oposto.

Quanto às implicações enfrentadas no exercício da profissão por ser mulher, todos/as os/as entrevistados/as afirmaram que, quanto à convivência entre docentes, não há problemas decorrentes da diferença sexual. Mas, nesse espaço "amigável", a percepção das mulheres é de invisibilidade. Num habitat natural deles, o domínio do território também no ambiente informal de trabalho deixa a mulher numa situação de invisibilidade, o que é constatado em um dos trechos do discurso de uma professora: "Na academia existe muito respeito entre todos, mas nas salas dos professores, quando todos estão juntos, eles perdem a noção de que lá existem mulheres e falam como se estivessem somente entre eles" (professora 4).

Quanto à percepção dos homens, um deles declara: "Em uma sala que tem apenas homens, fica-se mais à vontade para falar sobre futebol, carro, mulheres, piadas, e quando tem professoras, por educação e para interagir melhor, fala-se de assuntos gerais" (professor 1).

Nota-se que a presença delas no ambiente masculino exigiu adaptações de ambos os sexos. Para uma convivência harmoniosa, eles formam um grupo para conversar sobre assuntos "masculinos", e elas formam outro grupo, no qual, segundo eles, há mais intimidade e onde os assuntos particulares são tratados. Na percepção dos homens, é preciso adequar os conteúdos e a linguagem para tornar possível algum tipo de interação com elas. Para isso, evitam falar sobre os assuntos que são inerentes à comunidade de homens e adotam "assuntos gerais".

Isso sugere que existam interações próprias de homens e de mulheres, num convencionalismo próprio da construção histórica da identidade feminina e masculina. Tais categorias são fechadas e homogêneas, sendo facilmente notadas quando essa homogeneidade é rompida pela presença de alguém "estranho", ou seja, que pertença a outro sexo - uma mulher. Os assuntos coincidentes são somente aqueles relacionados ao ambiente acadêmico.

810 Estudos Feministas, Florianópolis, 21(3): 793-816, setembro-dezembro/2013 
${ }^{65}$ YANNOULAS, 2008.

${ }^{66}$ ALMEIDA, 1998
As mulheres são testadas e colocadas à prova pelos professores quanto à sua competência para aprovação de trabalhos científicos. No que tange ao reconhecimento pelos feitos do sexo oposto, algumas professoras relataram que suas realizações não ganham tantos "parabéns" quanto aquelas dos homens.

Juntamente com minha equipe de alunos, mandei 3 artigos e os 3 foram aprovados. Mas nenhum deles chegou pra mim pra falar parabéns. O que a gente faz... é como se não fosse importante...ninguém dá valor, mas quando eles fazem algo, todo mundo chega pra eles pra falar parabéns (professora 3).

Os mecanismos meritocráticos existentes no mundo acadêmico parecem não prestigiar igualmente o trabalho de professoras e professores. Como aponta Yannoulas, ${ }^{65}$ a relevância e pertinência à ciência das contribuições científicas dos homens são muito mais valorizadas que a produção feminina. A eles é dada a notoriedade e o reconhecimento dos seus pares em virtude de tais feitos. A elas cabe apenas a silenciosa satisfação pessoal.

Os homens, em sua totalidade, não percebem nenhum tipo de discriminação quanto à visibilidade dada ao trabalho das mulheres. Isso mostra que a meritocracia é necessária para legitimar a incorporação das mulheres na universidade, mas não é condição suficiente para garantir a equidade de gênero no meio científico. Muitas delas afirmaram que os seus feitos são invisíveis aos olhos dos outros professores, coordenadores e gestores da instituição, enquanto o mesmo não ocorre com os homens, pois qualquer coisa que eles façam ganha notoriedade.

A produção acadêmica foi apontada por elas como sendo alvo de competição por parte dos professores, como explicitado por uma das professoras: "Quando tem chamadas de trabalhos, eles sempre perguntam quantos a gente enviou e quantos foram aceitos, como uma forma de acompanhar o nosso desempenho em relação ao deles" (professora 2).

Essa competitividade científica, segundo Almeida, ${ }^{66}$ é uma estratégia adotada pelos homens para se manter no domínio e no controle de seu território, mantendo longe do saber o dominado. Quando as mulheres conseguem a legitimação do seu saber no mundo científico, através de publicações de trabalhos, elas escapam do círculo de convivência habitual e saem do confinamento institucional.

Os relatos de professores e professoras convergiram ao considerarem que as mulheres, para entrar nesse mundo masculino, precisam romper com alguns modelos femininos. Mudanças no vestuário, como não usar vestidos, ou mesmo no comportamento, como não ser muito sorridente, são 
${ }^{67}$ SCHEINBINGER, 2001, p. 150.

${ }^{68}$ SCHEINBINGER, 2001. estratégias adotadas por elas para parecem mais sérias e evitar chamar a atenção da maioria masculina para sua feminilidade.

Como argumenta Scheinbinger, 67 "o abandono dos atavios da feminilidade" é importante para que ela seja levada a sério como cientista e evitar uma atenção indesejável à sua sexualidade. A indiferença com relação à sua aparência é uma ameaça à expressão da feminilidade da mulher, mas é uma forma de garantir a ela a sua permanência na área. Na academia, a expressão do eu passa pela necessidade de ser reconhecida como competente e mais profissional para nortear a atribuição feita pelos outros. Essa é uma estratégia de expressão do eu que não deseja que o outro julgue a professora pelo seu gênero. O agir como mulher está em constante disputa com os valores e práticas projetados pela construção cultural da imagem de uma cientista. ${ }^{68}$

Para atrair mais mulheres para a Ciência da Computação e Informática, os professores afirmaram que seria necessária maior conscientização de que as mulheres tem as mesmas habilidades que os homens para essa área. Formação de ligas de mulheres e grupos de estudo específicos seriam interessantes para que elas se consolidassem mais nessa área da ciência. Além disso, a divulgação dos trabalhos femininos seria importante para dar visibilidade à competência delas.

Algumas professoras declararam que, para atrair mais estudantes mulheres, seria necessário divulgar mais no ensino médio o curso e as oportunidades de trabalho na área, que precisam de um "toque feminino". Elas reconhecem que muito tem sido feito em congressos e formação de grupos para chamar a atenção da sociedade e da academia para essa situação, tentando criar estratégias de atraí-las. Nota-se que tanto os professores quanto as professoras parecem creditar ao feminismo da diferença ${ }^{69} \mathrm{O}$ caminho para aumentar o número de mulheres na área. No entanto, como adverte a mesma autora, dar excessiva publicidade aos feitos das mulheres, fazer grupos apenas de mulheres, ressaltar qualidades femininas (toque feminino), como uma forma de atração, só serve para reafirmar velhos estereótipos que sempre justificaram sua exclusão na construção do saber científico.

\section{Considerações Finais}

Os relatos obtidos de professores/as da computação e informática apontam que há segregação das mulheres nessa área da ciência. As percepções a respeito dela são diferenciadas para os homens e mulheres. Para eles, a discriminação das mulheres ocorre em virtude de uma

812 Estudos Feministas, Florianópolis, 21(3): 793-816, setembro-dezembro/2013 
dificuldade delas com disciplinas de Lógica e Matemática, o que faz com que, ainda na graduação, sejam julgadas como menos capazes. É com naturalidade que eles falam da baixa inserção e permanência delas na área, o que é atribuído aos processos de socialização que determinam o lugar de cada sexo nos espaços sociais e também no âmbito da ciência. Embora inconscientemente, outras formas sutis de discriminação são exercidas por eles, exercendo pressões sobre elas no que tange ao trabalho e ao convívio na área. Ser mulher em uma área da ciência cujo território é de grande maioria de homens gera formas acumulativas de discriminação que provocam a segregação delas não apenas pelos professores do curso, mas também por alunos e outros profissionais que trabalham nas instituições em que lecionam, que conferem maior reconhecimento ao trabalho do sexo masculino. Para vencerem a resistência à presença feminina nesse espaço configurado para homens, elas precisam juntar-se às outras, adotar mecanismos para minimizar a sua feminilidade e, passivamente, buscar o reconhecimento do seu saber fora dos limites institucionais. Se a sociedade prima pelo valor da igualdade, a meritocracia no ambiente acadêmico não tem se revertido em igualdade de gênero dentro das instituições de ensino. $O$ trabalho dos homens continua valendo mais que o trabalho das mulheres.

A tolerância e a passividade com que elas lidam com essa situação mostram o quanto, mesmo inconscientemente, elas já estão adaptadas. Privilegiar o ponto de vista das mulheres é fundamental em estudos como este, de forma que as diversas situações de discriminação, ainda impostas pelo sexo, sejam reveladas. Constatações como essas precisam ser reveladas para que a forma como a divisão sexual do trabalho se apresenta em cada área específica seja conhecida e gere motivações para a mudança dessa história de relações de gênero.

Como afirma Schienbinger," "a história descarta o mito do progresso inevitável no que diz respeito às mulheres na ciência". Como esse progresso não acontece naturalmente, é preciso evitar os recuos e os conformismos inerentes a uma situação imposta historicamente, de modo a evitar que esse número de mulheres na área continue decrescendo.

\section{Referências}

ALMEIDA, Jane Soares de. Mulher e educação: a paixão pelo possível. São Paulo: UNESP, 1998.

BEAUVOIR, Simone. O segundo sexo. Rio de Janeiro: Difel: Difusão Editorial, 1975.

BRASIL. Coordenação de Aperfeiçoamento de Pessoal de Nível Superior. Aumenta o número de mulheres com pós- 
graduação. Brasília, DF, 7 mar. 2007. Disponível em: < http://www.capes.gov.br/servicos/sala-de-imprensa/36noticias/1699> Acesso em: 7 out. 2010.

Instituto Nacional de Estudos e Pesquisas Educacionais Anísio Teixeira. Assessoria de Imprensa do Inep. Mulheres estão em maior número na educação superior. Disponível em: <http://portal.inep.gov.br/c/journal/view_article_content? groupld $=10157$ \&articleld $=13337$ \&versio $\bar{n}=1.0 .>$ Acesso em: 8 out. 2010.

Homens têm mais interesse por cursos superiores da área de exatas e as mulheres naqueles de serviços e educação. Brasília, ano 4, n. 132, 17 mar. 2006. Disponível em: <http://www.inep.gov.br/informativo/pdf/informativol 32. pdf. $>$. Acesso em: $1^{\circ}$ out. 2010.

Ministério da Ciência e Tecnologia. Diretório dos Grupos de pesquisa no Brasil. Súmula Estatística 2010. Disponível em: < http://dgp.cnpq.br/censos/sumula estatistica/ 2010/pesquisadores/pesquisadores.htm > . Acesso em: 20 dez. 2011.

BROWN, Betina Lankard. "Women and minorities in high-tech careers." Eric Digest, n. 226, não paginado, 2001 Disponível em: <http://www.calpro-online.org/eric/docs/ dig226.pdf $>$. Acesso em 7 out. 2010.

BRUSCHINI, Cristina. (Org.). Uma questão de gênero. Rio de Janeiro: Rosa dos Tempos; São Paulo: Fund. Carlos Chagas, 1992.

CAMPOS, Maria Christina S. de S.; SILVA, Vera L. G. da (Org.) Feminização do magistério: vestígios do passado que marcam o presente. Bragança Paulista: Edusf, 2002.

CARVALHO, Maria Eulina. P. de. "Gênero e carreiras universitárias: o que mudou?" Trabalho apresentado no Seminário Internacional Fazendo Gênero 7. UFSC, 28 a 30, ago. 2006.

CASTRO, Fábio de. "Debandada feminina". Agência FAPESP. 10 jan. 2007. Disponível em: <http://www.agencia.fapesp. $\mathrm{br} /$ materia/6583/entrevistas/debandada-feminina.htm $>$. Acesso em: 5 out. 2010.

FONTOURA, Natália de Oliveira; GONZALEZ, Roberto. "Aumento da participação das mulheres no mercado de trabalho: mudança ou reprodução da desigualdade." Boletim Mercado de Trabalho. Brasília: Ipea, n. 41, p. 21-26, 2009.

GARCIA, Marta I. González; SEDEÑO, Eulalia Pérez. "Ciencia Tecnología y Género", OEI, n. 2, ene./abr. 2002. Disponível em: <http://www.oei.es/revistactsi/numero2/varios2.htm>. Acesso em: 20 out. 2011.

GLOVER, Judith. "Women and Scientific Employment: Current Perspectives from the UK." Science Studies, v. 15, n. 1, p. 29-45, 2002.

HARDING, Sandra. Ciência y feminism. Madrid: Ediciones Morata, 1996.

814 Estudos Feministas, Florianópolis, 21(3): 793-816, setembro-dezembro/2013 
HENWOOD, Flis. "From the Woman Question in Technology to the Technology Question in Feminism Rethinking Gender Equality in IT Education." European Journal of Women's Studies, v. 7, n 2, p. 209-222, 2000.

HIRATA, Helena; KERGOAT, Danièle. "Novas Configurações da Divisão Sexual do Trabalho." Cadernos de Pesquisa, São Paulo, n. 132, p. 595-609, set./dez., 2007.

INSTITUTO BRASILEIRO DE GEOGRAFIA E ESTATÍSTICA. SIS 2009: em dez anos, cai de $32,4 \%$ para $22,6 \%$ o percentual de famílias vivendo com até meio salário mínimo per capita. 9 out. 2009. Disponível em: <http://www.ibge.gov.br/ home/presidencia/noticias/noticia_visualiza.php?id_noticia $=1476$ eid $>$. Acesso em: 7. out. 2010 .

SIS 2010: Mulheres mais escolarizadas são mães mais tarde e têm menos filhos. 17 set. 2010. Disponível em: < http://saladeimprensa.ibge.gov.br/noticias?view= noticia\&id $=1$ \&busca $=1$ \&idnoticia $=1717>$. Acesso em: 15 nov. 2010.

KELLER, Evelyn Fox. Reflexiones sobre género y ciência. Tradução de Ana Sánches. Valencia: Alfons el Magnànim, 1991.

LIMA, Betina Stefanello. Teto de vidro ou labirinto de cristal? As margens femininas das ciências. 2008. Dissertação (Mestrado em História) - Universidade de Brasília, Brasília, 2008.

LOURO, Guacira Lopes. "Gênero e magistério: identidade, história e representação." In: CATANI, Denice et al. Docência, Memória e Gênero: estudos sobre formação. 4. ed. São Paulo: Escrituras, 2003.

MARQUES, Fabrício. "Procuram-se mulheres. Prêmio concedido a pesquisadora da Unicamp chama a atenção para a queda do interesse feminino na computação." Pesquisa Fapesp, n. 132, p. 26-27, fev. 2007. Disponível em: < http:/ /revistapesquisa.fapesp.br/wp-content/uploads/2007/02/ 26a27-mulheres-132.pdf > Acesso em: 5 out. 2010.

MADALOZZO, Regina. "Gênero e Desigualdade." GVexecutivo, v. 7, n. 6, p. 34-39, nov./dez. 2008. Disponível em: <http://rae.fgv.br/sites/rae.fgv.br/files/artigos/5392.pdf

MANN, Chris; STEWART, Fiona. Internet communication and qualitative research: a handbook for researching on line. London: Sage, 2000.

MINAYO, Maria C. S. O desafio do conhecimento: pesquisa qualitativa em saúde. 10. ed. São Paulo: Hucitec, 2007.

MULHERES MAIS AFASTADAS DAS TECNOLOGIAS DE INFORMAÇÃO Ciência Hoje, 17 maio 2010. Disponível em: <http:// www.cienciahoje. pt/index.php?oid $=42641 \& o p=$ all $>$. Acesso em: 7 out. 2010

PERROT, Michelle. As mulheres ou os silêncios da história. Bauru: EDUSC, 2005. 
RAGO, Margaret. "Epistemologia feminista, gênero e história." In: PEDRO, Joana Maria;

GROSSI, Miriam (Orgs.). Masculino, feminino, plural: gênero na interdisciplinaridade. Florianópolis: Editora Mulheres, 1998. Disponível em: < http:// www.projcnpq.mpbnet.com. br/textos/epistemologia_feminista.pdf. > . Acesso em: 25 dez. 2011.

RAPKIEWICZ, Clevi Elena. "Informática: domínio masculino?" Cadernos Pagu, Campinas, n. 10, p. 169-200, 1998.

SAFFIOTI, Heleieth. "Rearticulando Gênero e Classe social." In: BRUSCHINI, Cristina; COSTA, Albertina de Oliveira (Orgs.). Uma questão de Gênero. São Paulo: Rosa dos Tempos; Fundação Carlos Chagas. 1992. p. 183-215.

SCHIEBINGER, Londa. O feminismo mudou a ciência? Tradução Raul Fiker. Bauru, SP: EDUSC, 2001. 384p.

SCOTT, Joan. "Gênero: uma categoria útil de análise histórica". Educação e Realidade, Porto Alegre, v. 20, n. 2, p. 5-19, jul./dez. 1995.

SOUZA, Maria Celeste Reis Fernandes de; FONSECA, Maria da Conceição Ferreira. "Discurso e 'verdade': a produção das relações entre mulheres, homens e matemática". Revista Estudos Feministas, Florianópolis, v. 17, n. 2, p. 596-613, maio/ago. 2009.

VELHO, Lea, LEÓN, Elena. "A construção social da produção científica por mulheres." Cadernos Pagu, Campinas, v. 10, p. 309-344, 1998.

WILSON, Fiona. "Can compute, won't compute: women's participation in the culture of computing." New Technology, Work and Employment, v. 18, n. 2, p. 127142, jul., 2003.

YANNOULAS, Silvia C. "Mulheres e ciência." Série Anis, n. 47, p. 1-8, mar., 2007. "Mulheres e Poder nas universidades." Série Anis, Brasília, Letras Livres, ano 8, n. 61, p.1-12, set. 2008.

${ }^{71}$ PERROT, 2005.

[Recebido em 2 de fevereiro de 2011 , reapresentado em 24 de março de 2012 e aceito para publicação em 4 de junho de 2012]

\section{Women in Computer Science}

Abstract: The aim of this study is to understand the inclusion of women in computer science. We sought to understand the perceptions of teachers and teachers about the inclusion of women in this area as well as the strategies used by them to assert themselves in this environment androcentric. Methodologically, there was a qualitative exploratory study using in-depth interviews with 12 teachers in the area. It was considered the perceptions of both sexes on the phenomenon, because as said Michelle Perrot, ${ }^{71}$ one can't think of the history of women without regard to men. The results indicate that there are subtle forms of discrimination and segregation of women in the area, requiring additional effort to have them the same recognition as men.

Key Words: Women; Science; Computation.

816 Estudos Feministas, Florianópolis, 21(3): 793-816, setembro-dezembro/2013 